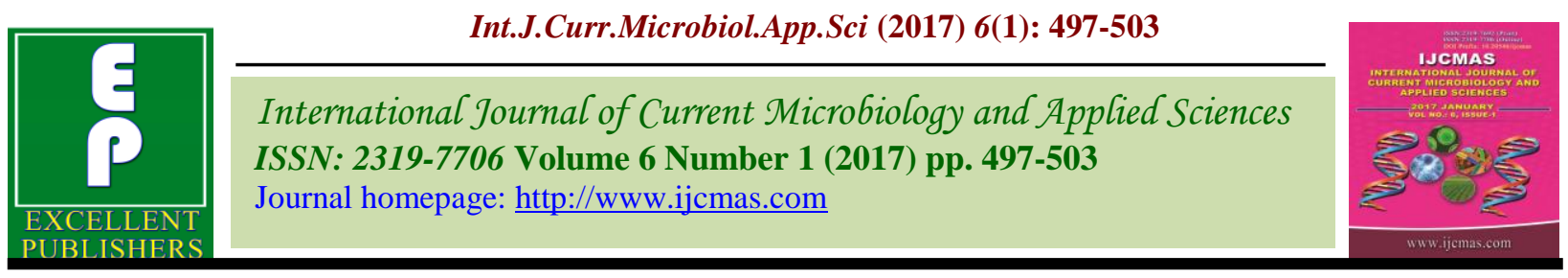

Original Research Article

http://dx.doi.org/10.20546/ijcmas.2017.601.059

\title{
Screening, Isolation and Identification of Lactobacillus Species from Dental Caries of Children
}

\author{
Sonu Singh Ahirwar ${ }^{1}$, M.K. Gupta ${ }^{2}$, Govind Gupta ${ }^{1}$ and $\operatorname{Vinod} \operatorname{Singh}^{1 *}$ \\ ${ }^{1}$ Department of Microbiology Barkatullah University Bhopal, Madhya Pradesh India \\ ${ }^{2}$ Peoples Dental Academy Bhanpur Bhopal, Madhya Pradesh India \\ *Corresponding author
}

\begin{abstract}
A B S T R A C T

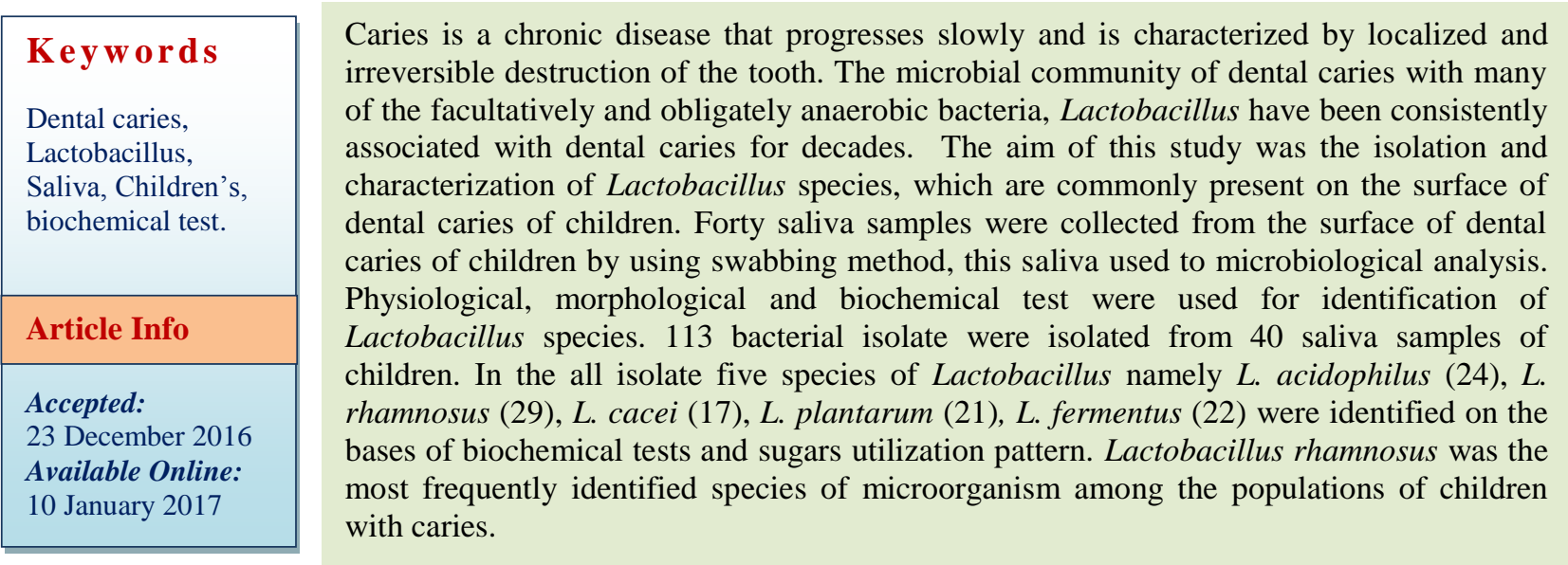

\section{Introduction}

Saliva plays an important role in oral health as it maintain the integrity of the oral hard and soft tissues, protects the oral tissue against immunogenic bacterial, fungal and viral infection (Siqueira et al., 2004).

Dental caries is one of the most prevalent diseases in the world. Worldwide, approximately 2.43 billion people (36\% of the population) have dental caries in their permanent teeth. The world health organization estimates that nearly all adults have dental caries at some point in time. In baby teeth it affects about 620 million people or $9 \%$ of the population (Vos et al., 2012).
They have become more common in both children and adults in recent year (Bagramian et al., 2009).

Dental caries can be defined as the localized destruction of susceptible dental hard tissues by acidic by-products from bacterial fermentation of dietary carbohydrates. In the development of caries a major role play bacteria of the Streptococcus and Lactobacillus genera which are acidogenic and aciduric (Chen and Wang, 2010).

Lactobacillus are characterized as Gram positive, usually non-motile, non - spore 
forming bacteria that produce lactic acid as a major or sole product of fermentative metabolism. The classification of lactic acid bacteria into different genera is largely based on morphology, mode of glucose fermentation, growth at different temperatures and configuration of the lactic acid produced ability to grow at high salt concentrations and acid or alkaline tolerance. The classification of the genus Lactobacillus remains uncertain and it consists of genetically heterogeneous strains which are difficult to classify by physiological and biochemical tests. Kandler and Weiss were classified Lactobacillus isolates from temperate regions according to their morphology, physiology and molecular characters (Kandler et al., 1986).

Historically, Lactobacilli were the first microorganisms implicated in dental caries development (Owen et al, 1949). They appear during the first years of a child's life, and are present in high numbers in saliva, on the dorsum of the tongue, mucous membranes, the hard palate, in dental plaque and, in fewer numbers, on tooth surfaces (Badet and Thebaud, 2008).

Lactobacilli absent from the oral cavity of new-borns appear during the first year of the life. McCarthy et al, observed the presence of this species in $50 \%$ of new-borns during their first year with a rate from 200 to 30000 bact/sample (Carthy et al., 1965).

In children without caries, the rate of salivary Lactobacilli varied among the different studies. Carlsson et al., considered that Lactobacilli became regularly present in 50\% of children and only since the age of 2 (Carlsson et al., 1975).

In the present study, we attempted to determine the Lactobacillus species which are commonly present in the dental caries of children and use the biochemical tests for classification and identification of it.

\section{Materials and Methods}

\section{Subjects}

Forty patients (23 male, 17 female) ranging in age 4 to 12 years, were selected for inclusion in the study. The samples used to this study were collected from the tooth of the patients diagnosed with dental caries by Physician. Dental caries indexes were recorded at the beginning of the study using WHO criteria and those with DMFT indexes between 9-15 were included in the study.

\section{Sample collection}

Samples were obtained between 8am and $12 \mathrm{pm}$, subjects were instructed not to drunk, eat, smoke or clean their teeth for 2hours before the sampling. Samples were collected from the infected area of the tooth was swapped with sterile cotton wool and saliva transferred to a sterile screw capped tube that contained $5 \mathrm{ml}, 1 \%$ saline water $(1 \% \mathrm{NaCl})$ with aseptic precautions, vortex mixed for $1 \mathrm{~min}$, to disperse the bacteria and sample were used to further laboratory examination.

\section{Isolation of bacteria}

For each sample, a 200-mL aliquot of saliva was spread on selective medium (MRS agar) that promotes the growth of Lactobacilli while suppressing growth of other bacteria. After incubation in incubator at $37^{\circ} \mathrm{C}$ for 48 hrs, a single colony with the most predominates morphology was picked and sub-cultured for $24 \mathrm{~h}$ on Rogosa agar under the same conditions (Rogosa et al., 1960).

\section{Identification of the Lactobacillus species}

The cultures were identified according to their morphological, cultural, physiological and biochemical characteristics (Kandler et al., 1986; Sharpe et al., 1979). The used tests were: Gram reaction; production of catalase, 
cytochrome oxidase and hydrogen peroxide; growth at $15^{\circ} \mathrm{C}$ and $45^{\circ} \mathrm{C}$ in 1 week; acid production from carbohydrates $(1 \% \mathrm{w} / \mathrm{v})$ - Larabinose, cellobiose, D-fructose, lactose, melezitose, melebiose, mannitol, D-mannose, raffinose, rhamnose, D-ribose, salicin, sorbitol, sucrose, trehalose and D-xylose in MRS broth devoid of glucose and beef extract with phenol red as indicator; production of acid and gas from $1 \%$ glucose (MRS broth without beef extract); Production of ammonia from arginine; nitrate reduction in nitrate broth; indole production in tryptone broth and growth on acetate agar.

\section{Catalase test}

A drop of 3\% hydrogen peroxide was placed on a clean microscopic slide. With a nicrome wire loop pick up cells from the centre of a well isolated colony of the test culture and transfer them into the drop of hydrogen peroxide. Both were mixed and observed for gas bubble production. The strains showing gram-positive and catalase negative isolates were identified at species level.

\section{Gas production from Glucose}

In order to further define homofermentative isolates, $\mathrm{CO} 2$ production from glucose test was performed. For this purpose, MRS broths and inverted Durham tubes were used. 50 $\mu$ of overnight cultures were transferred into the 8 $\mathrm{ml}$ test media. After incubation for 5 days at $30{ }^{\circ} \mathrm{C}$, gas accumulation in Durham tubes was taken as the evidence for $\mathrm{CO} 2$ production from glucose.

\section{Growth of isolates at $\left(15^{\circ} \mathrm{C}\right.$ and $\left.45^{\circ} \mathrm{C}\right)$}

The isolates were tested for their ability to grow in MRS broth at $15+1{ }^{\circ} \mathrm{C}$ for 7 days and $45^{\circ} \mathrm{C}$ by incubating for $24-48 \mathrm{~h}$. For this, $10 \mathrm{ml}$ of MRS broth tubes were inoculated @ $100 \mu 1$ of overnight Lactobacilli cultures. The development of turbidity in culture tubes was recorded as the ability of isolates to grow at $15^{\circ} \mathrm{C}$ and $45^{\circ} \mathrm{C}$ and results were noted as positive or negative.

\section{Arginine Hydrolysis}

Autoclaved arginine hydrolysis broth tubes were inoculated with the isolated cultures $(1 \%)$ and incubated at $37^{\circ} \mathrm{C}$ for $48 \mathrm{~h}$. After incubation, 3-5 drops of the Nessler's reagent were added to each test tube and observed for the change in colour (yellow to orange colour), indicating a positive result for arginine hydrolysis.

\section{Nitrate reduction}

Nitrate reduction is an important criterion for differentiating and characterizing different types of bacteria. Therefore, the isolates were incubated at $37{ }^{\circ} \mathrm{C}$ for $24 \mathrm{~h}$ in trypticase nitrate broth. After incubation, $0.5 \mathrm{~mL}$ each of sulphanilic acid $(0.8 \%$, in $5 \mathrm{~N}$-naphthylamine $(0.5 \%, \alpha$ Acetic acid) and in $5 \mathrm{~N}$ Acetic acid) were added into the tubes. The appearance of red or pink colour indicated the positive test for nitrate reduction and was recorded accordingly for the isolates tested in the present study.

\section{Citrate Utilization Test}

The isolates were inoculated in Simmons citrate agar incubated at $37{ }^{\circ} \mathrm{C}$ for $24 \mathrm{~h}$. After incubation, the appearance of blue coloration indicated the positive test for citrate utilization and was recorded accordingly for the isolates tested.

\section{Sugar fermentation}

Phenol red broth base medium was used as a medium for this test. Different sugar substrates namely, L- arabinose, cellobiose, D-fructose, lactose, melezitose, melebiose, 
mannitol, D-mannose, raffinose, rhamnose, D-ribose, salicin, sorbitol, sucrose, trehalose, D-xylose and glucose were used. $0.1 \mathrm{~g}(0.1 \%$ w/v) of each sugar substrate was added to 100 $\mathrm{ml}$ of the medium. $5 \mathrm{ml}$ of each mixture was transferred into each tube. For gas detection, Durham tube was inserted into the test tube containing glucose. All the tubes were sterilized for $15 \mathrm{~min}$ at $121^{\circ} \mathrm{C}$. The tubes were inoculated with a single colony of the bacteria under study. The positive reaction of the bacteria was indicated by the changes in the colour of the medium.

\section{Results and Discussion}

Colonies of lactic acid bacteria were observed on the surface of MRS plates. More than one colony was observed in most of the cases (figure.1). Cultural, physiological and morphological characteristics were examined with the help of microscope. Different types of species were observed, majority of them belonged to Gram+ve rods shaped bacteria (Table: 1). The purification of isolates was done by transferring Gram+ve rods shaped bacteria to the plates of selective media MRS respectively. These isolates were further sub cultured until pure isolates were obtained. Numbers of lactic acid bacterial cultures were isolated from saliva samples. After initial identification, most of them were determined as representative of the family Lactobacillaceae and genus Lactobacillus.

Hanging-drop wet method showed that the isolated bacteria were nonmotile. Therefore, these methods conformed that the bacteria under investigation was nonmotile. The nonmotile behaviour is a characteristic of Lactobacillus (Table 1).

Table.1 Morphological and simple physiological characteristics of Lactobacillus isolated from the saliva

\begin{tabular}{|c|c|c|c|c|c|}
\hline Species & L. acidophilus & L. rhamnosus & L. casei & L. plantarum & L. fermentum \\
\hline $\begin{array}{l}\text { Gram's stain } \\
\text { reaction }\end{array}$ & Gram's +Ve & Gram's +Ve & Gram's +Ve & Gram's +Ve & Gram's +Ve \\
\hline Motility & - & - & - & - & - \\
\hline Cell shape & Rod & Rod & Rod & Rod & Rod \\
\hline $\begin{array}{l}\text { Catalase } \\
\text { activity }\end{array}$ & - & - & - & - & - \\
\hline $\begin{array}{l}\text { Citrate } \\
\text { reaction }\end{array}$ & - & - & - & - & - \\
\hline $\begin{array}{l}\text { Nitrate } \\
\text { reaction }\end{array}$ & - & - & - & - & - \\
\hline $\begin{array}{l}\text { Colony } \\
\text { morphology }\end{array}$ & $\begin{array}{l}\text { Circular, } \\
\text { large, smooth, } \\
\text { glistering }\end{array}$ & $\begin{array}{l}\text { Circular, } \\
\text { large, smooth, } \\
\text { glistering }\end{array}$ & $\begin{array}{l}\text { White, and } \\
\text { creamish, } \\
\text { smooth, mucoid, } \\
\text { convex }\end{array}$ & $\begin{array}{l}\text { Circular, } \\
\text { white, } \\
\text { glistering, } \\
\text { convex }\end{array}$ & $\begin{array}{l}\text { Circular, } \\
\text { white, } \\
\text { glistering, } \\
\text { convex }\end{array}$ \\
\hline
\end{tabular}


Table.2 Biochemical characteristics of Lactobacillus species isolated from dental caries of children's

\begin{tabular}{|c|c|c|c|c|c|c|}
\hline \multicolumn{2}{|c|}{$\begin{array}{l}\text { Lactobacillus species } \\
\text { No. of isolates }\end{array}$} & $\begin{array}{l}\text { L. acidophilus } \\
24\end{array}$ & $\begin{array}{l}\text { L. rhamnosus } \\
29\end{array}$ & $\begin{array}{l}\text { L. casei } \\
17\end{array}$ & $\begin{array}{l}\text { L. plantarum } \\
21\end{array}$ & $\begin{array}{l}\text { L. fermentum } \\
22\end{array}$ \\
\hline \multicolumn{2}{|c|}{$\mathrm{CO} 2$ from glucose } & - & - & - & - & + \\
\hline \multicolumn{2}{|c|}{ NH3 from Arginine } & - & - & - & - & - \\
\hline \multirow{3}{*}{ Growth } & at $15^{\circ} \mathrm{C}$ & - & + & + & + & - \\
\hline & at $37^{\circ} \mathrm{C}$ & + & + & + & + & + \\
\hline & at $45^{\circ} \mathrm{C}$ & - & + & - & - & + \\
\hline \multicolumn{2}{|c|}{ Arabinose } & - & - & - & - & 8 \\
\hline \multicolumn{2}{|c|}{ Cellobiose } & + & + & - & + & - \\
\hline \multicolumn{2}{|c|}{ D-Mannose } & + & + & + & + & 11 \\
\hline \multicolumn{2}{|l|}{ Inositol } & - & - & - & - & - \\
\hline \multicolumn{2}{|l|}{ Lactose } & 10 & + & + & + & + \\
\hline \multicolumn{2}{|c|}{ Melezitose } & - & + & + & 17 & - \\
\hline \multicolumn{2}{|c|}{ Melibiose } & 16 & 6 & - & + & + \\
\hline \multicolumn{2}{|l|}{ Maltose } & + & + & 9 & + & + \\
\hline \multicolumn{2}{|c|}{ Mannitol } & - & + & + & + & - \\
\hline \multicolumn{2}{|c|}{ Raffinose } & 11 & - & - & + & + \\
\hline \multicolumn{2}{|c|}{ Rhamnose } & - & 18 & - & + & - \\
\hline \multicolumn{2}{|l|}{ Ribose } & - & + & + & + & + \\
\hline \multicolumn{2}{|l|}{ Salicin } & + & 22 & + & + & - \\
\hline \multicolumn{2}{|l|}{ Starch } & - & - & - & - & - \\
\hline \multicolumn{2}{|l|}{ Sucrose } & + & + & + & + & + \\
\hline \multicolumn{2}{|l|}{ Xylose } & - & - & - & - & - \\
\hline \multicolumn{2}{|l|}{ Glucose } & + & + & + & + & + \\
\hline
\end{tabular}

+: Positive reaction of all the isolates, -: Negative reaction. Numbers are the positive isolates. All the isolates fermented D- Glucose, D- Mannose, Lactose, Sucrose. 
Fig.1 Lactobacillus on MRS agar plate

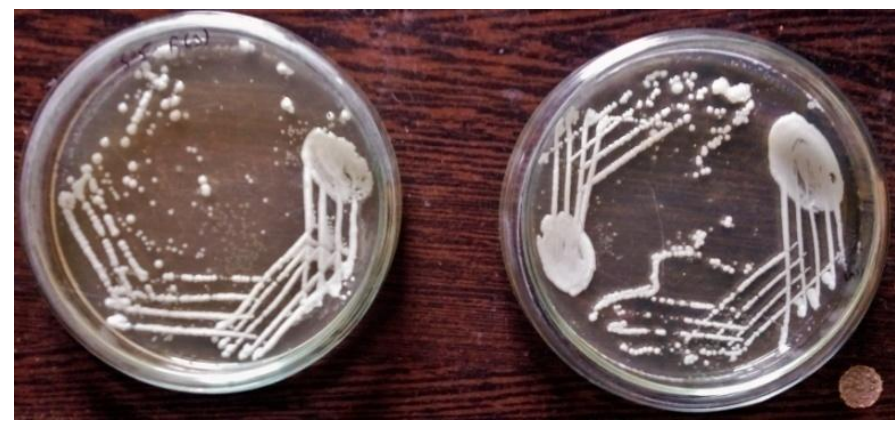

Fig.2 Sugar fermentation

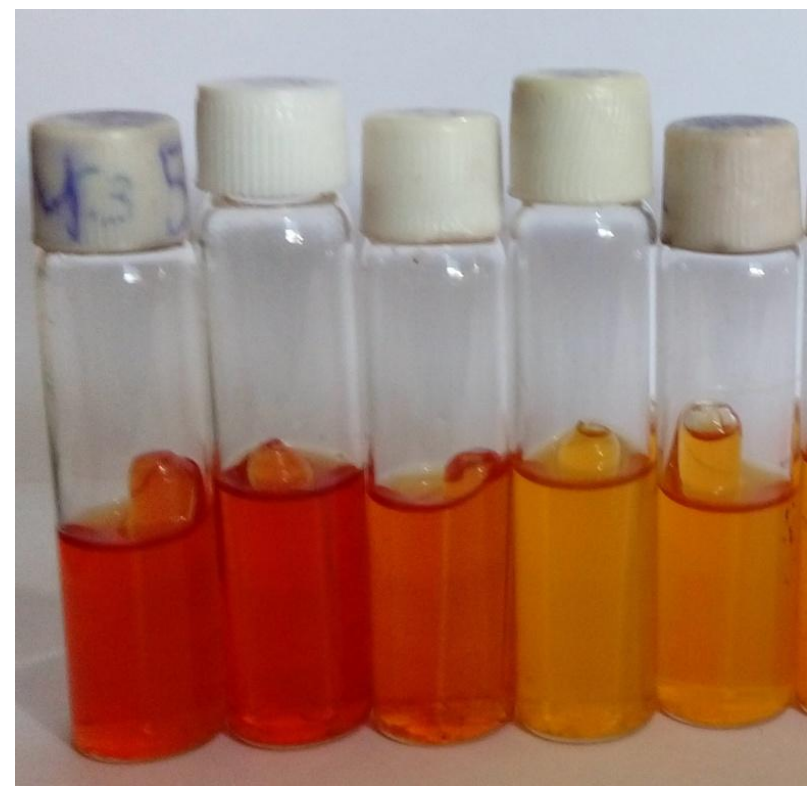

The catalase test is one of the most useful diagnostic tests for the recognition of bacteria due to their simplicity. In performing catalase test, no bubble was observed indicating that the isolated bacterium is catalase negative and could not mediate the decomposition of $\mathrm{H}_{2} \mathrm{O}_{2}$ to produce $\mathrm{O}_{2}$ (Table 1). Arginine hydrolysis, nitrate reduction, citrate utilization tests were perform, all isolates gave negative results (Table 1).

The main task of Carbohydrate fermentation test is to investigate the ability of bacteria to ferment different types of carbohydrate. Phenol red broth base medium was used as an indicator to differentiate the bacteria according to their patterns of carbohydrate utilization. Table 2 show the sugar fermentation patterns, total 113 bacterial strains were isolated. In total, 15 sugars were used for conformational identification of Lactobacilli and these were: L-arabinose, cellobiose, D-fructose, lactose, melezitose, melebiose, mannitol, D-mannose, raffinose, rhamnose, D-ribose, salicin, sorbitol, sucrose, trehalose and D-xylose. Different isolates showed different types of sugar utilization patterns where some tubes containing isolates and sugar turned yellow where as the other remained brown colored, indicating the positive and negative tests, respectively for sugar fermentation (Figure: 2). When these 
sugar utilization patterns were compared with those given for Lactobacillus species in the Bergey's Manual of Determinative Bacteriology, the isolates were tentatively identified as L. acidophilus, L. rhamnosus, $L$. casie, L. plantarum, L. fermentum. Hence, five different species within Lactobacillus genera in the saliva sample obtained from dental caries were confirmed in the present results.

In conclusion, in the current study we are isolate five species of Lactobacillus namely $L$. acidophilus, L. rhamnosus, L. casie, L. planturam, L. fermentum from dental caries of children. Lactobacillus rhamnosus is predominant in all isolated species, and play important role in dental caries progration.

\section{Acknowledgements}

This work was supported by a grant from RGNF-UGC India. We thanks to Dr Abhishek Gupta, Director of CMBT Bhopal India, who was provide us laboratory facility.

\section{References}

Badet, C. and Thebaud, N.B. 2008. Ecology of Lactobacillus in the oral cavity: A review of literature. Ope Micro J., 2: 38-48.

Bagramian, R.A., Garcia-Goday, F., Volpe, A.R. 2009. "The global increase in dental caries. A pending public health crisis." Ame J. Dent., 22(1): 3-8.

Carlsson, J., Grahnen, H., Jonsson, G. 1975. Lactobacilli and streptococci in the mouth of children. Caries res., 9: 333-339.
Chen, F. and Wang, D. 2010. Novel technologies for the prevention and treatment of dental caries: a patent survey. Expert Opin. Ther. Pat., 20: 681694.

De Man, Rogosa, J.C., M.E. Sharpe. 1960. A medium for the cultivation of lactobacilli, J. Appl. Bacteriol., 23(1), 130-135.

Kandler, O., Weiss, N. 1986. Microbiology of mesu, a traditional fermented bamboo shoot product, In: Bergey's Manual of Systematic Bacteriol. Sneath PHA, Mair NS, Sharpe ME, Holt JG (Eds). Baltimore: Williams, Wilkins 2: 1209 1234.

Mc Carthy, C., Snyder, M.L., Parker, R.B. 1965. The indigenous oral flora of man. I: The newborn to the 1-year-old infant. Arch. Oral Biol., 10: 61-70.

Owen, O.W. 1949. A study of bacterial counts (lactobacilli) in saliva related to orthodontic appliances; a preliminary report. Am. J. Orthod., 35: 672-678.

Sharpe, M.E., T.F. Fryer, D.G. Smith. 1979. Identification of Lactic Acid Bacteria. In: Identification Methods for Microbiologists, E. M. Gibbs, F. A. Skinner (Eds), London: Academic Press, 233-259.

Siqueira, L., Mustachhi, Z., Nicolau, J. 2004. Electrolyte concentrations in saliva of children aged 6-10 years with down syndrome. Oral surg. Oral med. Oral pathol. Oral radiol. Endod., 98:76-79.

Vos, T. 2012. "Years lived with disability (YLDs) for 1160 sequelar of 289 diseases and injuries 1990-2010: a systematic analysis for the global burden of disease study 2010." Lancet, 380(9859): 2163-96.

\section{How to cite this article:}

Sonu Singh Ahirwar, M.K. Gupta, Govind Gupta, Vinod Singh. 2017. Screening, Isolation and Identification of Lactobacillus Species from Dental Caries of Children. Int.J.Curr.Microbiol.App.Sci. 6(1): 497-503. doi: http://dx.doi.org/10.20546/ijcmas.2017.601.059 